\title{
Leptin downregulates expression of the gene encoding glucagon in alphaTC1-9 cells and mouse islets
}

\author{
L. Marroquí • E. Vieira • A. Gonzalez • A. Nadal • \\ I. Quesada
}

Received: 31 July 2010 /Accepted: 19 November 2010 /Published online: 14 January 2011

(C) Springer-Verlag 2011

\begin{abstract}
Aims/hypothesis Leptin, released by adipocytes, can modulate glucose homeostasis through direct actions on pancreatic alpha and beta cells. Although this hormone rapidly regulates alpha cell exocytosis, its long-term effects on glucagon gene expression are currently unknown.

Methods We analysed glucagon mRNA levels and protein content in alphaTC1-9 cells and isolated mouse islets cultured with leptin, as well as in islets from mice treated in vivo with leptin. We also studied the involvement of the signal transducers and activators of transcription (STAT) pathway by western blot, immunofluorescence and interference RNA. Results Leptin incubation $(0.0625-18.75 \mathrm{nmol} / \mathrm{l})$ for $24 \mathrm{~h}$ inhibited glucagon gene expression in alphaTC1-9 cells. This inhibitory effect was also observed in isolated mouse islets cultured with leptin, as well as in islets from mice treated with leptin for 5 days. In contrast, no changes were detected in islets from $d b / d b$ mice, which lack leptin receptors. Leptin treatment also reduced the glucagon protein content in alphaTC1-9 cells and mouse islets. Moreover, leptin induced phosphorylation of STAT3 and its translocation to the nucleus, which was confirmed by western blot analysis in alphaTC1-9 cells and by immuno-
\end{abstract}

Electronic supplementary material The online version of this article (doi:10.1007/s00125-010-2024-1) contains supplementary material, which is available to authorised users.

L. Marroquí • E. Vieira · A. Gonzalez • A. Nadal $\cdot$ I. Quesada $(\bowtie)$ Instituto de Bioingeniería, Universidad Miguel Hernandez, Avenida de la Universidad, s/n,

03202 Elche, Spain

e-mail: ivanq@umh.es

L. Marroquí · E. Vieira · A. Gonzalez · A. Nadal $\cdot$ I. Quesada Centro de Investigación Biomédica en Red de Diabetes y Enfermedades Metabólicas Asociadas (CIBERDEM), Spain URL:www.ciberdem.org fluorescence in isolated alpha cells. Interestingly, the effect of leptin on glucagon mRNA levels was significantly reduced by Stat 3 knockdown. In contrast, pharmacological inhibition of the phosphoinositide 3-kinase pathway did not affect leptin actions.

Conclusions/interpretation Our results demonstrate that leptin can regulate glucagon gene expression in alpha cells via a STAT3 pathway, and are important for understanding the role of leptin in glucose homeostasis.

Keywords Diabetes · Glucagon · Glucose homeostasis · Islets · Leptin · Pancreatic alpha cells
Abbreviations
JAK Janus kinase
PI3K Phosphoinositide 3-kinase
siRNA small interfering RNA
SOCS Suppressor of cytokine signalling
STAT Signal transducers and activators of transcription

\section{Introduction}

Glucagon, which is synthesised and secreted by pancreatic alpha cells in the islets of Langerhans, plays a fundamental role in glucose homeostasis. In contrast to the glucoselowering effect of insulin, glucagon increases blood glucose levels by inducing gluconeogenesis and glycogenolysis, and promoting hepatic glucose output [1, 2]. Since glucagon secretion is mainly stimulated at low plasma glucose levels [3, 4], this process allows for restoration of normoglycaemia. Thus glucagon, along with insulin, constitutes a bihormonal system that maintains glucose concentrations within the physiological range [5]. In addition to the protective effect against hypoglycaemia, glucagon also counterbalances insulin actions on glucose 
metabolism. In diabetes, the alpha cell secretory response is altered. Type 1 and late type 2 diabetic individuals can present with hyperglucagonaemia, which aggravates the hyperglycaemic state derived from the impaired insulin response [6]. In these patients, the suppression of glucagon release at high plasma glucose levels can also be altered, promoting postprandial hyperglycaemia. In addition, impairment of the glucagon secretory response at low glucose concentrations could contribute to hypoglycaemic episodes, particularly in patients under insulin treatment [6].

Leptin, which is released from the adipose tissue, has a key function in the control of food intake, energy expenditure, metabolism and body weight [7]. Even though most of these functions are mediated by the action of leptin on the hypothalamus, this hormone also exerts important effects on peripheral tissues. In the endocrine pancreas, leptin can work as an important modulator of glucose homeostasis through direct actions on alpha and beta cells [8-10]. Leptin modulates beta cell function by suppressing insulin gene expression and insulin secretion $[8,11,12]$. Recently, it has been shown that leptin receptors are expressed in mouse and human alpha cells, and that leptin inhibits electrical activity, $\mathrm{Ca}^{2+}$ signalling and exocytosis in these cells [10]. The possibility that leptin has a regulatory effect on glucagon release is further supported by mouse models with defects in leptin signalling, since these animals develop hyperglucagonaemia $[13,14]$. Thus leptin released from adipose tissue plays an important role in islet function and glucose homeostasis. Indeed, it has been proposed that defects in this leptin-mediated regulation may be involved in the development of diabetes in obese individuals $[9,15]$. Additionally, it has been suggested that leptin might be used as a therapeutic tool in type 1 diabetes, given that induction of hyperleptinaemia by adenoviral transfer of the leptin gene as well as by leptin administration corrects hyperglucagonaemia in mouse models of type 1 diabetes, improving their glycaemic control $[16,17]$. Therefore, it is essential to improve knowledge of communication between adipose tissue and pancreatic alpha cells, in order to understand the role of leptin in glucose homeostasis and to design potential therapeutic strategies in diabetes. In the present study, we demonstrate that leptin can regulate the expression and synthesis of glucagon in the pancreatic alpha cell, a process that involves participation of signal transducers and activators of transcription (STAT)3. Thus, leptin plays an important role in alpha cell function.

\section{Methods}

Islet isolation and cell culture All protocols were approved by our Animal Care Committee according to national regulations. Female C57BL/6 mice (8-12 weeks old) were killed by cervical dislocation and islets were then isolated by collagenase digestion [3, 10]. When necessary, single cell suspensions were obtained from the islets by trypsin enzymatic digestion. Isolated cells or islets were cultured in RPMI 1640 (Sigma, Madrid, Spain) supplemented with $10 \%$ FBS (vol./vol.), $100 \mathrm{IU} / \mathrm{ml}$ penicillin, $0.1 \mathrm{mg} / \mathrm{ml}$ streptomycin and $11 \mathrm{mmol} / \mathrm{l}$ D-glucose [10]. The glucagonreleasing alphaTC1-9 cell line was purchased from American Type Cultures Collection (ATCC CRL-2350; Barcelona, Spain). AlphaTC1-9 cells were grown in DMEM (Invitrogen, Barcelona, Spain) supplemented with $4 \mathrm{mmol} / \mathrm{l} \mathrm{L}-$ glutamine, $16 \mathrm{mmol} / \mathrm{l}$ glucose, $19 \mathrm{mmol} / 1 \mathrm{NaHCO}_{3}, 10 \%$ FBS, $15 \mathrm{mmol} / 1 \mathrm{HEPES}$ and $0.1 \mathrm{mmol} / \mathrm{l}$ non-essential amino acids. Recombinant mouse leptin (Calbiochem, Madrid, Spain) was dissolved following the manufacturer's instructions and applied in the above-mentioned media with different glucose concentrations. Experiments were performed at $37^{\circ} \mathrm{C}$ and, except when indicated, at $2.8 \mathrm{mmol} / 1$ glucose. Islets or cells were cultured for $1 \mathrm{~h}$ in RPMI medium prior to each in vitro treatment.

In vivo leptin treatment Vehicle (PBS) or leptin $(500 \mathrm{ng} / \mathrm{g}$ body weight) was administered to mice by i.p. injection at 09:00 and 21:00 hours for five consecutive days [8]. To eliminate the possibility that the reduced food intake induced by leptin in the treated animals might induce changes in glucagon gene expression, a pair-fed control was also included. In this group, the food intake of vehicletreated mice was matched to that consumed by the leptintreated mice on the previous day [17]. When islets were isolated, they were immediately subjected to analysis of glucagon mRNA levels.

Semiquantitative RT-PCR Total RNA was isolated using a kit (RNeasy Mini; Qiagen, Madrid, Spain). Extracted RNA was quantified by measuring optical density at 260 and $280 \mathrm{~nm}$ and used to generate cDNA using Expand Reverse Transcriptase (Roche, Mannheim, Germany). Of each RT reaction, $2 \mu \mathrm{l}$ was used as input for the PCR. Primers are detailed in Electronic supplementary material (ESM Table 1). PCR amplification was performed using Taq-DNA polymerase (Invitrogen) under the following conditions: $15 \mathrm{~s}$ at $94^{\circ} \mathrm{C}, 30 \mathrm{~s}$ at $55^{\circ} \mathrm{C}$ and $1 \mathrm{~min}$ at $72^{\circ} \mathrm{C}$. $18 \mathrm{~S}$ was amplified as an internal control. PCR products were subjected to agarose gel electrophoresis.

Quantitative real-time PCR Quantitative PCR assays were performed using LightCycler (Roche). Reactions were carried out in a final volume of $10 \mu \mathrm{l}$, containing $200 \mathrm{nmol} / \mathrm{l}$ of each primer, $100 \mathrm{nmol} / \mathrm{l}$ of endogenous control primer, $1 \mu \mathrm{l}$ cDNA and $1 \times$ SYBR Green I (LightCycler FastStart DNA Master ${ }^{\text {PLUS }}$; Roche). Samples were subjected to the following conditions: $10 \mathrm{~min}$ at $95^{\circ} \mathrm{C}$, 
40 cycles of $10 \mathrm{~s}$ at $95^{\circ} \mathrm{C}, 7 \mathrm{~s}$ at $60^{\circ} \mathrm{C}$ and $12 \mathrm{~s}$ at $72^{\circ} \mathrm{C}$, and a melting curve of 63 to $95^{\circ} \mathrm{C}$ with a slope of $0.1^{\circ} \mathrm{C} / \mathrm{s}$. The housekeeping gene Rplp0 (ribosomal protein large $\mathrm{P} 0$ ) was used as the endogenous control for quantification [18]. Leptin treatment did not affect expression of this gene (ESM Fig. 1). Further information about the reaction efficiency of glucagon and the housekeeping gene can be found in ESM Fig. 1. The resulting values were expressed as relative expression compared with control levels $\left(2^{-\Delta \Delta \mathrm{C}_{\mathrm{t}}}\right)$ [19]. Primers are described in ESM Table 2.

Immunocytochemistry Cells were first fixed with Bouin's solution for $5 \mathrm{~min}$ and then dehydrated for $3 \mathrm{~min}$ with $30 \%$, $50 \%$ and $70 \%$ (vol./vol.) ethanol. Triton X-100 (0.5\% [vol./ vol.]) was used to permeabilise the cells. To reduce nonspecific binding, cells were first pre-incubated with a blocking buffer (5\% [vol./vol.] serum in PBS) for $45 \mathrm{~min}$ before applying primary antibodies in a buffer containing $1 \%$ (vol./vol.) serum. The following primary antibodies were applied overnight at $4^{\circ} \mathrm{C}$ : mouse anti-glucagon $(1: 500$; Sigma) and rabbit anti-STAT3 (phospho Y705) (1:100; Abcam, Cambridge, UK) antibodies. After washing, appropriate combinations of secondary antibodies conjugated with Alexa Fluor dyes (1:500; Invitrogen) were applied for $2 \mathrm{~h}$ at room temperature. Images were acquired using a laser confocal microscope (LSM 510; Zeiss, Barcelona, Spain) equipped with a $\times 40$ oil immersion objective. Fluorescence was analysed with confocal imaging software. Given that nuclear fluorescence changes were relatively small, the intensity settings were increased to visualise basal phosphorylated STAT3 fluorescence. Consequently, a basal fluorescence signal is observed in the cytosol in resting conditions.

Western blot analysis Cell pellets were obtained by centrifuging at $1,000 \mathrm{~g}$ for $10 \mathrm{~min}$ and resuspended in $200 \mu \mathrm{l}$ Cell Lysis Buffer (Cell Signaling Technology, Danvers, MA, USA). Cell extracts were subjected to SDS-PAGE (10\% gels). Pre-stained SDS-PAGE standards were included for molecular mass estimation. Transfer to polyvinylidene fluoride membranes was performed at $125 \mathrm{~mA}$ for $90 \mathrm{~min}$ in a buffer with $2.5 \mathrm{mmol} / \mathrm{l}$ Tris base, $9 \mathrm{mmol} / \mathrm{l}$ glycine and $20 \%$ (vol./vol.) methanol. After the membranes were blocked with $2 \%$ (vol./vol.) non-fat dry milk, they were incubated with rabbit polyclonal anti-actin (1:1,000; Sigma), anti-STAT3 (phospho Y705) (1:500; Abcam), anti-STAT3 (1:500; Abcam) or anti-suppressor of cytokine signalling (SOCS)3 (1:500; Abcam) antibodies, before being incubated with a peroxidase-conjugated donkey anti-rabbit (GE Healthcare, Barcelona, Spain) antibody. Protein bands were revealed using a kit (ECL Chemiluminescence Reagents; GE Healthcare, Barcelona, Spain).
Isolation of cytosolic and nuclear fractions Fractions were isolated as previously described [20]. Briefly, cell pellets were obtained by centrifuging at $200 \mathrm{~g}$ for $10 \mathrm{~min}$ and lysed with TBN buffer: $10 \mathrm{mmol} / \mathrm{l}$ Tris- $\mathrm{HCl}, 140 \mathrm{mmol} / \mathrm{l} \mathrm{NaCl}$, $3 \mathrm{mmol} / 1 \mathrm{MgCl}_{2}, 0.5 \%$ (vol./vol.) NP40, $\mathrm{pH} 6.5$ and protease inhibitor cocktail (Complete; Roche). The homogenate was centrifuged for $5 \mathrm{~min}$ at $3,300 \mathrm{~g}$ and $4{ }^{\circ} \mathrm{C}$. The supernatant fraction included the cytosolic fraction. The pellet was washed three times with TBN buffer and resuspended in $100 \mu \mathrm{l}$ cell lysis buffer (Cell Signaling Technology). To assess the purity of each fraction, actin $(1: 1,000 ;$ Sigma $)$ and TATA binding protein $(1: 1,000$; Abcam) were used in the western blots as cytosolic and nuclear markers, respectively.

Interference RNA Small interfering RNA (siRNA) treatment was performed in alphaTC1-9 cells and in islet cells dispersed in isolated cells or in small clusters as previously described [21]. Cells were transfected overnight with $50 \mathrm{nmol} / 1$ siRNA (Silencer Pre-designed STAT3; Applied Biosystems, Madrid, Spain) or $50 \mathrm{nmol} / \mathrm{l}$ FAM-labelled negative control 1 siRNA (Silencer; Applied Biosystems) in Opti-MEM I (Invitrogen) culture medium without antibiotics and $0.2 \%$ (vol./vol.) lipofectamine 2000 (Invitrogen). The following Stat3 siRNA 5'-3' sequences were used: GGAUCUAGAACAGAAAAUGtt, sense; CAUUUUCUGUUCUAGAUCCtg, antisense. After overnight incubation, transfection medium was replaced by DMEM culture medium with the different test agents.

Glucagon content Islets were first preincubated for $60 \mathrm{~min}$ at $37^{\circ} \mathrm{C}$ in $0.5 \mathrm{ml}$ Krebs-Ringer bicarbonate buffer supplemented with $15 \mathrm{mmol} / \mathrm{l}$ HEPES, $0.5 \% \mathrm{BSA}$ and $5.6 \mathrm{mmol} / \mathrm{l}$ glucose, $\mathrm{pH}$ 7.4. Afterwards, batches of either ten islets or $1 \times 10^{6}$ alphaTC1-9 cells were incubated for $24 \mathrm{~h}$ at $37^{\circ} \mathrm{C}$ in $0.5 \mathrm{ml}$ of the above-mentioned DMEM supplemented with $2.8 \mathrm{mmol} / \mathrm{l}$ glucose and the different test agents. Then the medium was aspirated and the islets or cells lysed with $50 \mu \mathrm{l}$ lysis buffer (70\% [vol./vol.] ethanol, $0.4 \%$ [vol./ vol.] $\mathrm{HCl}$ at $30 \%$ [vol./vol.], $29.6 \%$ [vol./vol.] distilled water) and incubated overnight at $4^{\circ} \mathrm{C}$. Samples were centrifuged for $5 \mathrm{~min}$ at $1,000 \mathrm{~g}$ and the supernatant fraction collected for analysis. Glucagon was detected by ELISA using a commercial kit (YK090; Gentaur, Brussels, Belgium). Total protein was determined by the Bradford method.

Statistical analysis Data are shown as mean \pm SE. Student's $t$ test or one-way ANOVA were performed to compare the means of two different groups or more than two groups, respectively, with a level of significance of $p<0.05$. ANOVA analysis was followed by Dunnett's or Tukey's post tests when all the groups were compared with a control or for pairwise comparisons, respectively. 


\section{Results}

Leptin inhibits glucagon gene expression in alphaTC1-9 cells and mouse islets To analyse the role of leptin in longterm regulation of glucagon, we studied its effect in mouse islets as well as alphaTC1-9 cells, which have been validated as a good model to study alpha cell function $[10,22]$. As previously reported [10], alphaTC1-9 cells have similar levels of the long form of the leptin receptor to those found in mouse islets (ESM Fig. 2). Since it has been previously demonstrated that glucose can regulate glucagon gene expression in alphaTC1-6 cells [23], we evaluated the effect of leptin on glucagon mRNA levels in the presence of several glucose concentrations. As shown in Fig. 1a, glucose produced a U-shaped inhibition, with a maximal effect at $11.2 \mathrm{mmol} / \mathrm{l}$. Leptin $(6.25 \mathrm{nmol} / \mathrm{l})$ reduced glucagon mRNA levels in all glucose concentrations analysed. Leptin inhibition varied from $10 \%$ to $35 \%$ depending on the glucose concentration, with a maximum effect at $2.8 \mathrm{mmol} / \mathrm{l}$ glucose, which diminished with increasing glucose levels (Fig. 1b). Since the effect was higher at low glucose concentrations, the majority of experiments were performed at $2.8 \mathrm{mmol} / \mathrm{l}$ glucose. Study of the temporal course showed a significant effect after $12 \mathrm{~h}$ leptin treatment at $2.8 \mathrm{mmol} / \mathrm{l}$ glucose and after $24 \mathrm{~h}$ at $11.2 \mathrm{mmol} / \mathrm{l}$ glucose (Fig. 1c, d). Incubation for $48 \mathrm{~h}$ further increased the effect. A dose-response analysis from 0.000625 to $18.75 \mathrm{nmol} / 1$ leptin $(0.01-300 \mathrm{ng} / \mathrm{ml})$ showed a maximum effect at $0.625 \mathrm{nmol} / 1$ (Fig. 1e). The effect of insulin, which is a well-known inhibitor of glucagon gene transcription [22], was also confirmed. Analysis of the glucagon content revealed that leptin inhibition of glucagon gene transcription was also manifested at the protein level (Fig. 1f). Thus, these results demonstrate that leptin can regulate glucagon gene expression in alphaTC1-9 cells.

We next tested the role of leptin in isolated mouse islets. It has been shown that, in contrast to insulin, glucose does not seem to modulate glucagon gene transcription in rodent islets [24]. Thus we performed the experiments at $2.8 \mathrm{mmol} / \mathrm{l}$ glucose to avoid potential contributions of islet paracrine signalling at high glucose concentrations [2]. Incubation of islets with 0.625 and $6.25 \mathrm{nmol} / 1$ leptin at $2.8 \mathrm{mmol} / \mathrm{l}$ glucose for $24 \mathrm{~h}$ resulted in a marked decrease of glucagon mRNA levels (Fig. 2a). Although insulin produced an inhibitory effect, it was not statistically significant. Conversely, leptin did not produce any changes in the isolated islets obtained from $d b / d b$ mice, which lack leptin receptors (Fig. 2b). Consistent with the results in alphaTC1-9 cells, leptin also decreased glucagon protein content in isolated islets (Fig. 2c). We also studied whether these effects take place in vivo. For this purpose, mice were treated for 5 consecutive days with two daily i.p. injections of leptin or with vehicle (PBS) [8]. A group of pair-fed
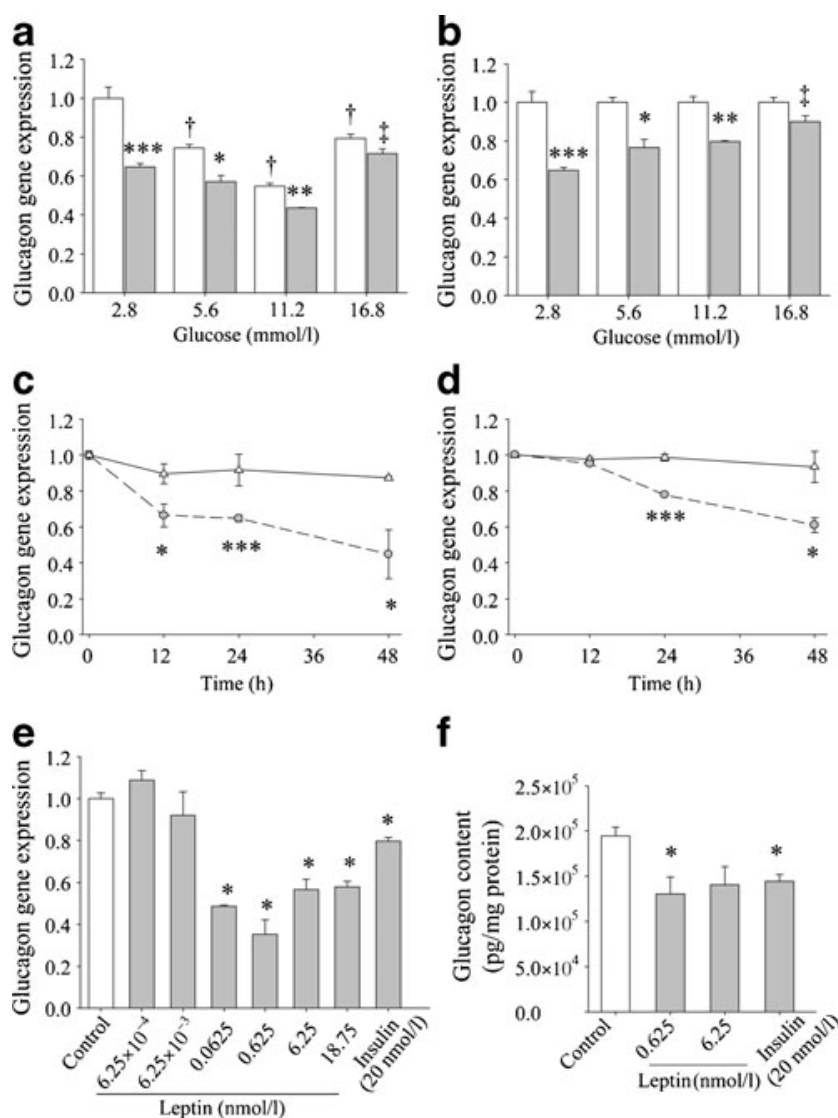

f

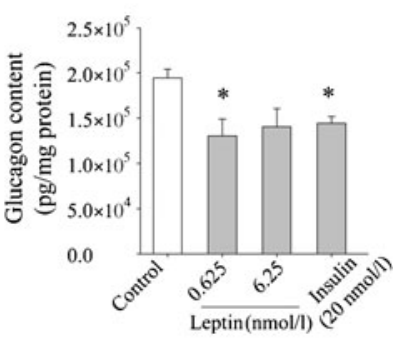

Fig. 1 Leptin effect on glucagon gene expression in alphaTC1-9 cells. a Effect of leptin incubation $(6.25 \mathrm{nmol} / 1)$ (grey bars) or vehicle (white bars) for $24 \mathrm{~h}$ on glucagon mRNA levels at different glucose concentrations $(n=3-9)$. Data are expressed relative to control ( $2.8 \mathrm{mmol} / 1$ glucose without leptin). b The effect of leptin from above results (a) was expressed relative to each glucose concentration. c Effect of leptin $(6.25 \mathrm{nmol} / \mathrm{l})$ (circles, dotted line) or vehicle (triangles, continuous line) at different incubation times in the presence of 2.8 and (d) $11.2 \mathrm{mmol} / \mathrm{l}$ glucose. Data are expressed relative to expression at $0 \mathrm{~h}$ ( $n=3-4$ for each condition). e Effect of different leptin concentrations and insulin after incubation for $24 \mathrm{~h}$ in $2.8 \mathrm{mmol} / \mathrm{l}$ glucose $(n=4-5)$. f Glucagon content after incubation for $24 \mathrm{~h}$ with different stimuli in $2.8 \mathrm{mmol} / \mathrm{l}$ glucose $(n=6-8)$. Controls without leptin included the vehicle (PBS). Rplp0 was used as the endogenous control for quantification. Data are shown as mean \pm SE. ${ }^{*} p<0.05,{ }^{* *} p<0.01$ and ${ }^{* * *} p<0.001$ for each value vs its control without leptin; ${ }^{\dagger} p<0.05$ for each glucose concentration vs $2.8 \mathrm{mmol} / \mathrm{l}$; ${ }^{\star} p=0.06$; analysis (a-d) by Student's $t$ test and by ANOVA followed by Dunnett's test $(\mathbf{a}, \mathbf{e}, \mathbf{f})$

mice treated with vehicle was also included. After 5 days, body weight decreased in the leptin and pair-fed groups (Fig. 2d). The isolated islets from leptin-treated animals contained about $42 \%$ lower glucagon mRNA levels than those of controls (Fig. 2e). Conversely, glucagon mRNA levels in the pair-fed group remained similar to those of controls. Given that plasma glucose levels were around 6.0 to $6.6 \mathrm{mmol} / 1$ in leptin-treated and pair-fed groups after 5 days (ESM Table 3), the decreased glucagon gene 


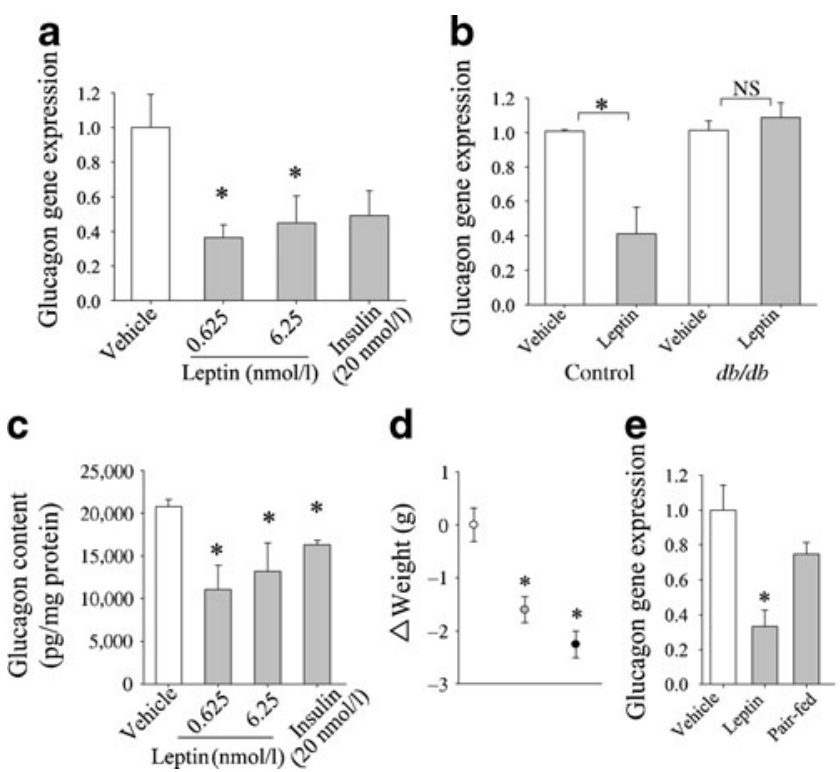

Fig. 2 Leptin inhibits glucagon gene expression in mouse pancreatic islets. a Effect of leptin and insulin incubation for $24 \mathrm{~h}$ on glucagon gene expression in $2.8 \mathrm{mmol} / \mathrm{l}$ glucose in isolated mouse islets $(n=3-$ 6). b Effect of leptin $(6.25 \mathrm{nmol} / \mathrm{l})$ in isolated islets from control and $\mathrm{db} / \mathrm{db}$ mice in $2.8 \mathrm{mmol} / \mathrm{l}$ glucose $(n=3-4)$. c Glucagon content after incubation for $24 \mathrm{~h}$ with different stimuli in $2.8 \mathrm{mmol} / \mathrm{l}$ glucose $(n=4)$. d Body weight changes in mice treated with vehicle (white circle) or leptin $(500 \mathrm{ng} / \mathrm{g}$ body weight; grey circle) after 5 days of treatment ( $n=4-5$ animals in each group). A pair-fed vehicle-treated (black circle) group was also included. e Glucagon gene expression in isolated islets from the different mouse groups after 5 days of treatment ( $n=8-10$ from five animals). No statistical differences were found between the vehicle and pair-fed groups. Vehicle included PBS. Results are expressed relative to the control (vehicle). Rplp0 was used as the endogenous control for quantification in each experiment. Data are shown as mean \pm SE. ${ }^{*} p<0.05$ for comparison of each value with its control (vehicle); analysis by Student's $t$ test (b) for each group, by ANOVA followed by Dunnett's test $(\mathbf{a}, \mathbf{c})$ and by Tukey's post test $(\mathbf{d}, \mathbf{e})$

expression would seem to have been due to leptin treatment and not to changes in plasma glucose levels or food intake. Although several mechanisms could mediate this in vivo effect, the above-mentioned in vitro results (Fig. 2a) point to a direct effect of leptin on alpha cells. Therefore all these findings in alphaTC1-9 cells and mouse islets indicate that leptin can regulate glucagon gene expression, particularly at low to intermediate glucose levels.

Leptin induces activation and nuclear translocation of STAT3 in alphaTC1-9 cells and mouse alpha cells Leptin can produce several cellular actions that are mediated by numerous signalling cascades [25]. Among them, the Janus kinase (JAK)-STAT pathway plays a key role in the regulation of gene expression in different cellular systems, as STAT proteins work as transcription factors [7]. Although we detected the transcript of multiple STAT proteins in alphaTC1-9 cells (Fig. 3a), we focused on STAT3, given its widespread role in leptin regulation of gene expression. Incubation of alphaTC1-9 cells with $6.25 \mathrm{nmol} / 1$ leptin induced phosphorylation of STAT3 (Fig. 3b, c). Once phosphorylated, STAT3 forms dimers that are translocated from the cytosol to the nucleus, where they bind to promoter regions of different target genes, inducing changes in gene transcription [25]. To analyse whether leptin induces translocation of phosphorylated STAT3 to the nucleus in alphaTC1-9 cells, we performed a western blot with purified cytosolic and nuclear fractions. While phosphorylated STAT3 was slightly increased in the cytosol, it was clearly accumulated in the nucleus after leptin treatment (Fig. 4a, b). Consistent with this nuclear accumulation of phosphorylated STAT3, levels of total STAT3 protein decreased in the cytosol, while they increased in the nucleus (Fig. 4a, b). Next, to study the translocation of phosphorylated STAT3 in mouse alpha cells, we measured immunofluorescence in isolated islet cells (Fig. 4c-f). While no changes were observed in glucagon-positive cells treated with vehicle, the fluorescence associated with phosphorylated STAT3 increased in the nucleus of the cells exposed to leptin (Fig. 4c-f). After $1 \mathrm{~h}$ of leptin treatment, the nuclear : cytosol fluorescence ratio was increased by $\sim 70 \%$ in alpha cells, indicating nuclear accumulation of phosphorylated STAT3 (Fig. 4g). These results therefore indicate that leptin induces the phosphorylation and nuclear translocation of STAT3.

Stat3 downregulation reduces the leptin effect on glucagon gene expression in alphaTC1-9 cells and islet cells To test whether leptin-induced STAT3 activation was involved in regulation of glucagon gene expression, we used siRNA to knockdown Stat3 gene expression as previously reported [26-28]. As shown in Fig. 5a, b, the treatment of alphaTC1-9 cells and islet cells with siRNA against Stat3 significantly decreased Stat 3 mRNA levels $(\sim 75 \%$ and $\sim 73 \%$, respectively) compared with cells treated with a scrambled siRNA (control siRNA). Interestingly, while leptin inhibited mRNA expression of glucagon in alphaTC1-9 cells and isolated islet cells treated with the control siRNA, leptin did not significantly reduce glucagon gene transcription in cells treated with siRNA against Stat3 (Fig. 5c, d). It has been indicated that leptin-induced STAT expression produces an increased expression of SOCS3 that inhibits the preproinsulin gene in INS-1 cells [12]. We therefore tested the potential participation of SOCS3 in the effect of leptin on glucagon gene expression (Fig. 6). However, we could not detect any significant increase in SOCS3 protein after stimulation with leptin in a similar temporal pattern (from $15 \mathrm{~min}$ to $6 \mathrm{~h}$ ) to that for STAT3 activation (Fig. 6a). Leptin treatment for $24 \mathrm{~h}$ also had no effect on SOCS3 protein levels (Fig. 6b) and Socs3 gene 

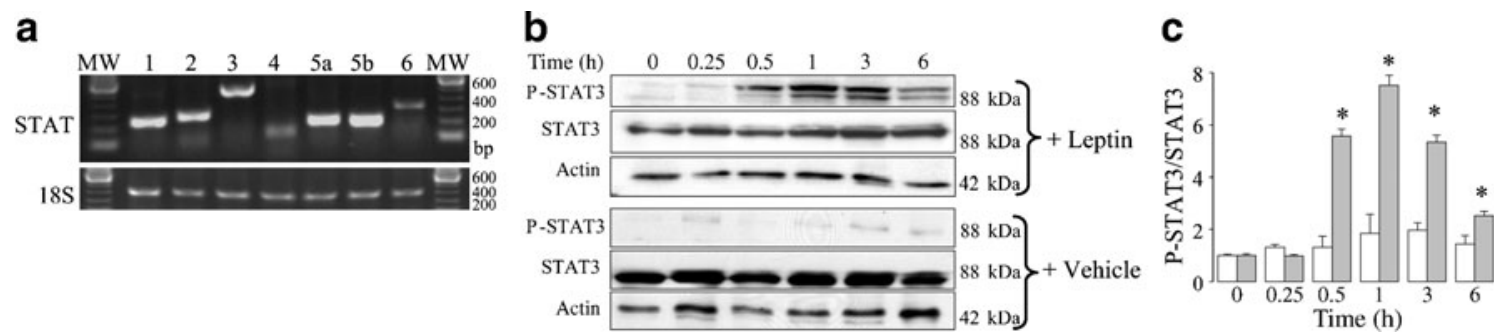

Fig. 3 Leptin induces STAT3 phosphorylation in alphaTC1-9 cells. a Levels of different STAT isoforms in alphaTC1-9 cells was analysed by semiquantitative PCR $(n=3)$. MW, molecular weight. b Western blot illustrating STAT3 phosphorylation (P-STAT3) after leptin $(n=5)$ or vehicle (PBS; $n=3$ ) treatment for the indicated time periods. $\mathbf{c}$ Relative densitometric quantification of western blots (b). Effect of leptin $(6.25 \mathrm{nmol} / \mathrm{l})$ (grey bars) or vehicle (white bars). Data are shown as mean \pm SE. ${ }^{*} p<0.05$ vs control (vehicle) using Student's $t$ test for each time expression (Fig. 6c). These results suggest that SOCS3 might not participate in the effect of leptin shown here. Since we have previously reported that phosphoinositide 3-kinase (PI3K) is involved in the effect of leptin on alpha cell stimulus-secretion coupling [10], we also analysed this pathway. However, application of two different PI3K inhibitors, LY 294002 and wortmannin, did not prevent the leptin action on glucagon mRNA levels (ESM Fig. 3), indicating that this pathway was unlikely to be involved. Thus these results show that STAT3 participates in the inhibitory effect of leptin on glucagon gene expression.

\section{Discussion}

It has been reported that leptin can modulate glucose metabolism by directly affecting the expression and secretion of insulin in the beta cell $[8,11]$. In addition, it was recently demonstrated that leptin rapidly inhibits alpha cell stimulus-secretion coupling and glucagon secretion via a PI3K-dependent pathway [10]. In the present study, we show that leptin also regulates alpha cell function in the long term, inhibiting glucagon gene expression via a pathway that involves STAT3. The in vitro effects were also observed in mice treated with leptin, indicating that alpha cell regulation by leptin also occurs in vivo. The current findings further support the idea that leptin can modulate glucose homeostasis through rapid non-genomic as well as long-term genomic effects on the two main cell types of the islet of Langerhans involved in glucose metabolism $[8,10,11]$. The inhibitory effect of leptin on synthesis and release of glucagon and insulin [8, 10] suggests that this hormone restrains the functional activity of alpha and beta cells in the short and long term, particularly at glucose concentrations (low and high, respectively) where these cell types are more active. Thus it is possible that leptin may prevent oversecretion from alpha and beta cells in situations where these cells are highly stimulated, which may favour homeostasis of glucose. In this regard, the inhibitory function of leptin on alpha and beta cells would be similar to that of somatostatin, which is secreted from pancreatic delta cells [29]. This inhibitory role of leptin in the islet is consistent with the fact that mouse models lacking this hormone or deficient in leptin receptors develop hyperinsulinaemia and hyperglucagonaemia $[13,14]$. In addition to the effect of this hormone on the synthesis and secretion of insulin and glucagon, leptin can also regulate the action of these islet hormones [30]. Moreover, leptin produces important effects on the hypothalamus and tissues involved in glucose homeostasis, such as the liver $[30,31]$. Thus, the role of leptin in glucose homeostasis and metabolism is complex and involves multiple cell types and organs.

Several genes are downregulated by leptin. In the hypothalamus, leptin suppresses the expression of the orexigenic peptides Agouti-related protein (Agrp) and neuropeptide Y (Npy) [7, 32, 33]. The hepatic levels of several mitochondrial respiratory proteins are also decreased by leptin [34]. Interestingly, leptin also affects gene expression in the islet, inhibiting preproinsulin transcription $[8,11]$. Our results show that glucagon is another target gene downregulated by leptin. This is consistent with the suppressive effect of other cytokines on glucagon gene expression [35]. Additionally, we also showed that STAT3 is involved in the leptin regulation of glucagon mRNA levels. In the majority of the above-mentioned cases, leptin actions are mediated by the JAK-STAT pathway. For instance, leptin-induced STAT3 proteins can bind to Agrp gene promoter, inhibiting its expression in cultured cells [33]. Other studies indicate that leptin-induced suppression of Npy and Agrp gene expression may involve STAT3, but also requires PI3K signalling [32]. In this regard, the PI3K pathway has been described in several alpha cell lines as mediating the inhibitory effect of insulin on glucagon gene 
Fig. 4 Leptin-induced nuclear translocation of phosphorylated STAT3 in alphaTC1-9 cells and alpha cells. a Western blot illustrating the phosphorylation of STAT3 (P-STAT3) after leptin treatment for the indicated time periods in separated cytosolic and (b) nuclear fractions of alphaTC1-9 cells $(n=3)$. Actin was used as cytosolic marker, TATA binding protein (TBP) as nuclear marker. Relative densitometric quantification of western blots is also shown. c Images of immunofluorescence to detect p-STAT3 (green) in glucagon-positive cells (red) at $0 \mathrm{~h}$ and $1 \mathrm{~h}$ of leptin treatment, with intensity quantified in arbitrary units (a.u.) (d and e, respectively). White arrows, positions where intensity profiles were analysed. Scale bars, $10 \mu \mathrm{m}$. f Images of immunofluorescence at 0 or $1 \mathrm{~h}$ of vehicle treatment as labelled. Scale bars, $10 \mu \mathrm{m}$. g The fluorescence intensity profile in leptin-treated cells $(6.25 \mathrm{nmol} / \mathrm{l})$ (grey bars) or vehicle (white bars), as nuclear/cytosol

fluorescence ratio from experiments shown in images $\mathbf{c}$ and f $(n=10-19$ cells in each condition). Data are shown as mean \pm SE. ${ }^{*} p<0.05$ ANOVA followed by Dunnett's test $(\mathbf{a}, \mathbf{b})$ and by Tukey's post test (g) a

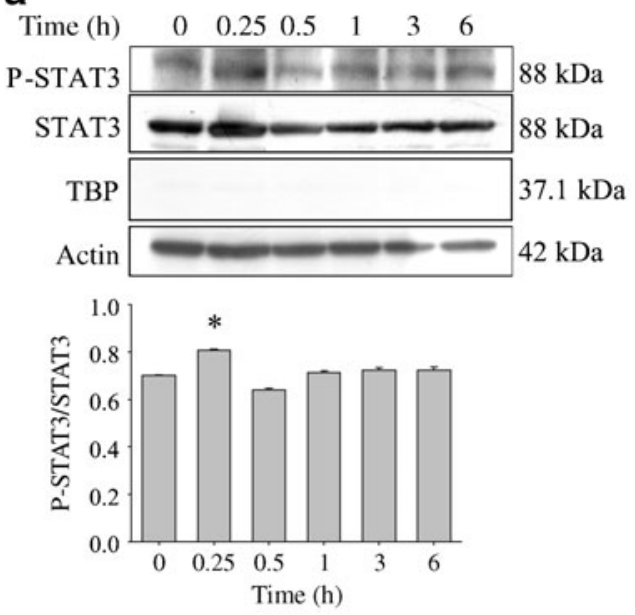

C
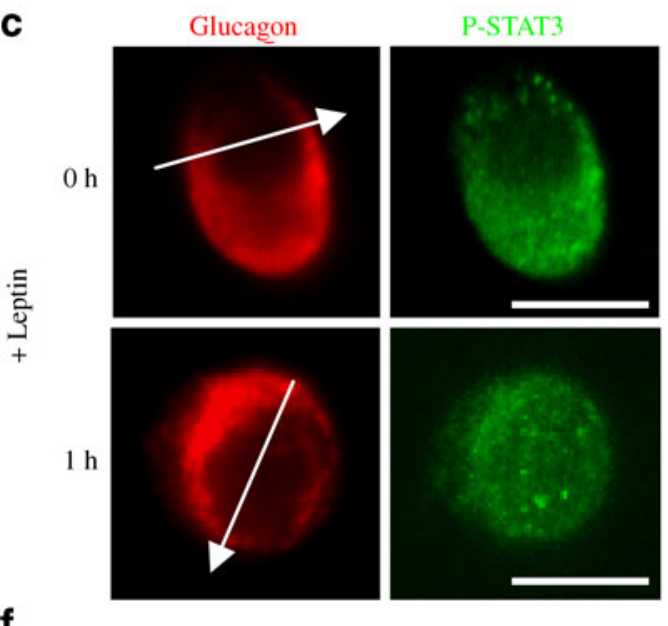

f

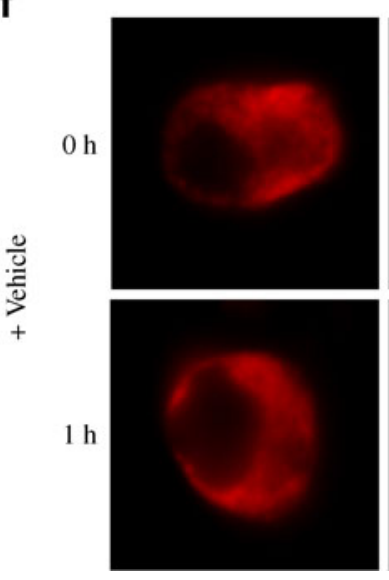

b
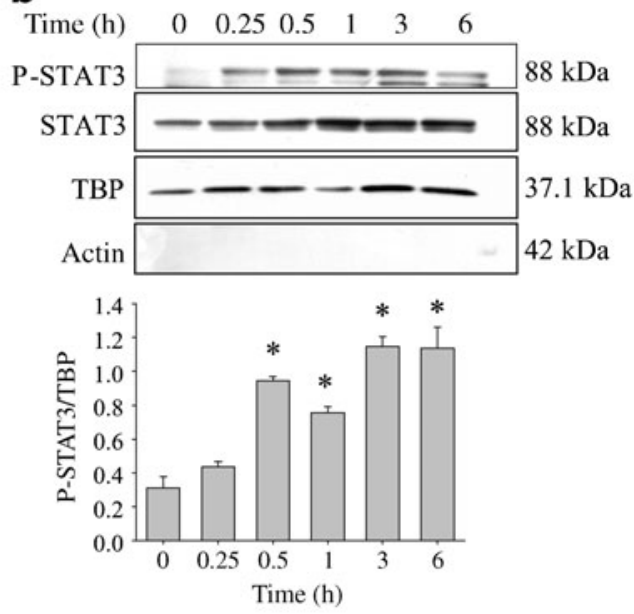

d
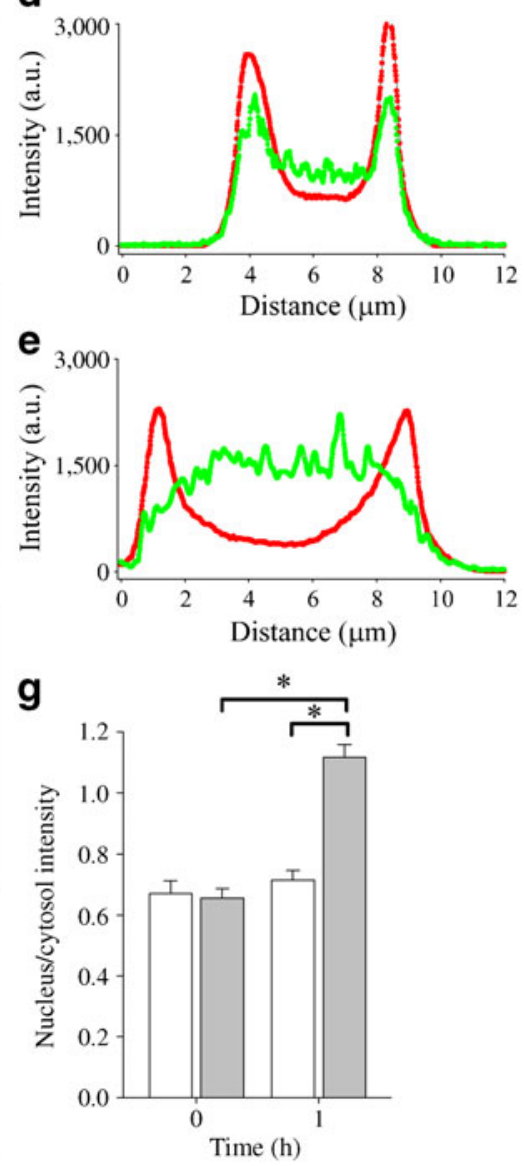

expression [22, 36]. However, the involvement of PI3K signalling in the transcriptional control of glucagon gene by leptin is unlikely, since the effect of this hormone was not modified in the presence of two different PI3K inhibitors. Alternatively, it has been proposed that SOCS3 is involved in leptin-induced STAT3-dependent inhibition of insulin gene expression in INS-1 cells [12]. Our results indicate that SOCS3 is unlikely to be involved in the regulation of glucagon gene expression by leptin, since this hormone did not produce any significant change in SOCS3 levels. Additionally, the suppression of several genes by STAT3 binding to their promoters has also been suggested for nitric-oxide synthase [26], p53 [37] and the gluconeogenic genes phosphoenolpyruvate carboxykinase 

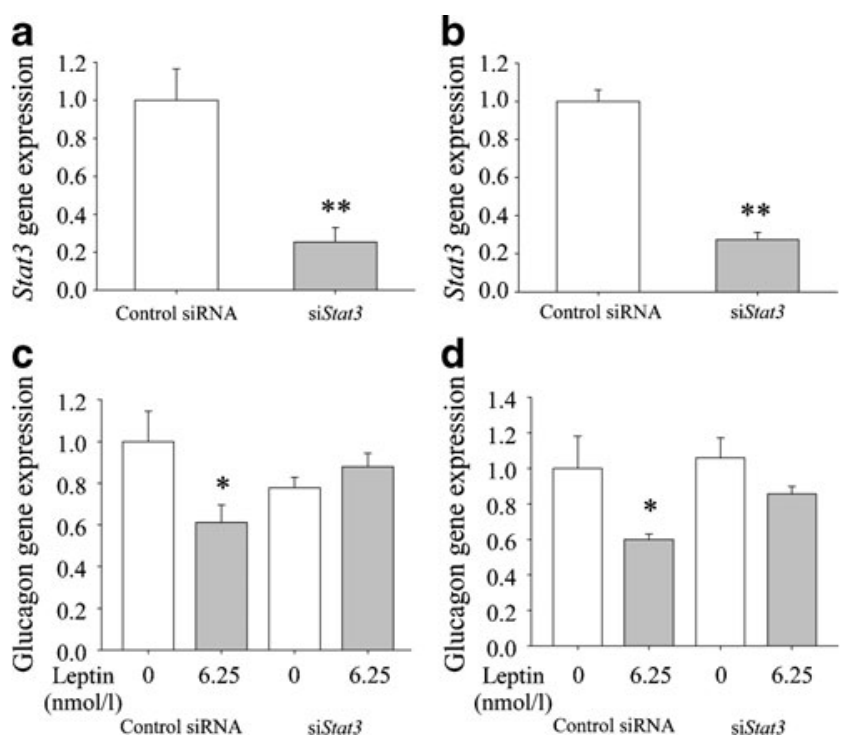

Fig. 5 Stat 3 knockdown reduces the leptin effect on glucagon gene expression. a Results of quantitative real-time PCR for Stat3 in alphaTC1-9 cells and (b) isolated islets cells treated with scrambled siRNA (control siRNA) and siRNA for STAT3 (siStat3) $(n=3$ in both experiments). c Effect of leptin for $24 \mathrm{~h}$ on glucagon mRNA levels in $2.8 \mathrm{mmol} / 1$ glucose in alphaTC1-9 cells and (d) isolated islets cells after treatment with control siRNA and siStat3 $(n=4-7, n=3-4$, respectively). Data are shown as mean \pm SE. ${ }^{*} p<0.05$ and $* * p<0.01$ compared with control, analysed by Student's $t$ test $(\mathbf{a}, \mathbf{b})$ and ANOVA followed by Tukey's post test $(\mathbf{c}, \mathbf{d})$

and glucose-6-phosphatase [27, 38]. However, although several direct or indirect mechanisms have been proposed for the action of leptin on gene expression, the exact mechanism is still under study. Therefore, further research is required to understand how leptin inhibits the expression of several genes, including glucagon, through the JAK-STAT pathway.

Substantial evidence supports the idea that insulin deficiency or resistance along with an absolute or relative excess of glucagon in diabetic patients can enhance hepatic glucose output, contributing to the hyperglycaemic state [6]. Consequently, different strategies have been developed to reduce glucagon secretion and/or antagonise glucagon actions [2]. In this regard, it has been proposed that leptin could be used in a therapeutic context, since either adenovirus-induced hyperleptinaemia or continuous leptin infusion reverses hyperglucagonaemia in animal models of type 1 diabetes, allowing for normalisation of glucose levels $[16,17]$. Although this lowering effect of leptin on plasma glucagon levels could be mediated by several processes, including central and peripheral responses [39], our present and previous findings [10] suggest that a direct action of leptin on the alpha cell may be involved. Thus, additional studies on the in vivo effect of leptin in the alpha cell would further contribute to the design of therapeutic strategies for type 1 diabetes.

The present study supports the idea that the communication between adipose tissue and the endocrine pancreas via leptin might be an important player for the short- and long-term regulation of glucose homeostasis. Since it has been proposed that alterations of this leptin-mediated communication in the beta cell may be involved in obesity-induced diabetes $[9,15]$, it would be interesting to study whether alpha cell regulation is also altered in this context.

\section{a}

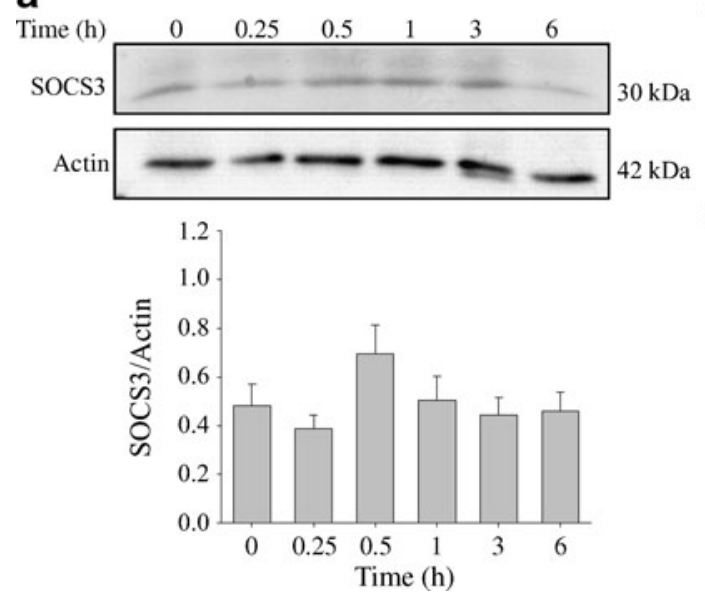

Fig. 6 SOCS3 protein levels and Socs 3 gene expression in alphaTC1-9 cells. a Western blot illustrating SOCS3 protein levels in alphaTC1-9 cells after leptin $(6.25 \mathrm{nmol} / \mathrm{l})$ treatment for the indicated time periods $(n=3)$, with relative densitometric quantification. b Western blot and relative densitometric quantification of SOCS3 protein levels in alphaTC1-9 cells after leptin treatment for $24 \mathrm{~h}(n=3)$. c Socs 3

b

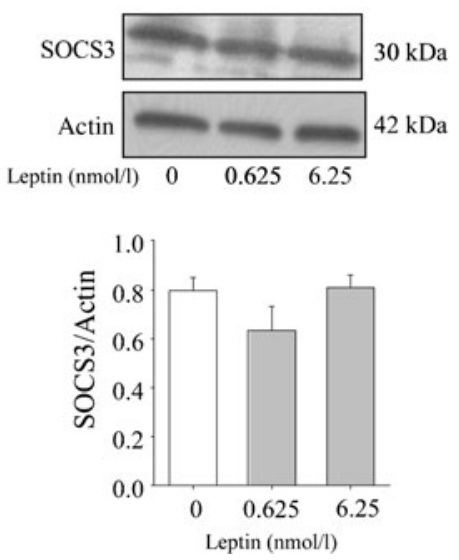

C

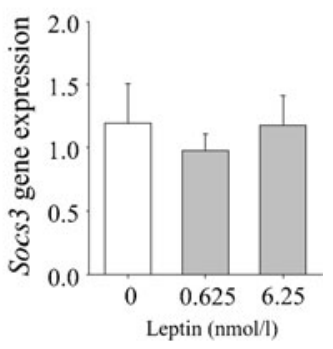

gene expression in alphaTC1-9 cells after incubation with leptin for $24 \mathrm{~h}$ $(n=3)$ were analysed by real-time PCR. Data are shown as mean \pm SE. In each experiment, the means were not found to be significant compared with control (vehicle or time 0) using ANOVA statistical analysis followed by Dunnett's post test 
Acknowledgements The authors thank A. B. Rufete and M. L. Navarro for their expert technical assistance. This work was supported by grants from the Ministerio de Educacion y Ciencia, Spain (BFU2007-67607; BFU2008-01492). Centro de Investigación Biomédica en Red de Diabetes y Enfermedades Metabólicas Asociadas (CIBERDEM) is an initiative of the Instituto de Salud Carlos III, Spain.

Duality of interest The authors declare that there is no duality of interest associated with this manuscript.

\section{References}

1. Gromada J, Franklin I, Wollheim CB (2007) Alpha-cells of the endocrine pancreas: 35 years of research but the enigma remains. Endocr Rev 28:84-116

2. Quesada I, Tuduri E, Ripoll C, Nadal A (2008) Physiology of the pancreatic alpha-cell and glucagon secretion: role in glucose homeostasis and diabetes. J Endocrinol 199:5-19

3. Nadal A, Quesada I, Soria B (1999) Homologous and heterologous asynchronicity between identified alpha-, beta- and delta-cells within intact islets of Langerhans in the mouse. J Physiol 517:85-93

4. Quesada I, Todorova MG, Alonso-Magdalena P et al (2006) Glucose induces opposite intracellular $\mathrm{Ca}^{2+}$ concentration oscillatory patterns in identified alpha- and beta-cells within intact human islets of Langerhans. Diabetes 55:2463-2469

5. Unger RH (1985) Glucagon physiology and pathophysiology in the light of new advances. Diabetologia 28:574-578

6. Dunning BE, Gerich JE (2007) The role of alpha-cell dysregulation in fasting and postprandial hyperglycemia in type 2 diabetes and therapeutic implications. Endocr Rev 28:253-283

7. Morris DL, Rui L (2009) Recent advances in understanding leptin signaling and leptin resistance. Am J Physiol Endocrinol Metab 297:E1247-E1259

8. Seufert J, Kieffer TJ, Habener JF (1999) Leptin inhibits insulin gene transcription and reverses hyperinsulinemia in leptindeficient $o b / o b$ mice. Proc Natl Acad Sci USA 96:674-679

9. Morioka T, Asilmaz E, Hu J et al (2007) Disruption of leptin receptor expression in the pancreas directly affects beta cell growth and function in mice. J Clin Invest 117:2860-2868

10. Tuduri E, Marroquí L, Soriano S et al (2009) Inhibitory effects of leptin on pancreatic alpha-cell function. Diabetes 58:1616-1624

11. Seufert J, Kieffer TJ, Leech CA et al (1999) Leptin suppression of insulin secretion and gene expression in human pancreatic islets: implications for the development of adipogenic diabetes mellitus. J Clin Endocrinol Metab 84:670-676

12. Laubner K, Kieffer TJ, Lam NT, Niu X, Jakob F, Seufert J (2005) Inhibition of preproinsulin gene expression by leptin induction of suppressor of cytokine signaling 3 in pancreatic beta-cells. Diabetes 54:3410-3417

13. Stearns SB, Benzo CA (1978) Glucagon and insulin relationships in genetically diabetic $(d b / d b)$ and in streptozotocin-induced diabetic mice. Horm Metab Res 10:20-23

14. Dunbar JC, Walsh MF (1980) Glucagon and insulin secretion by islets of lean and obese (ob/ob) mice. Horm Metab Res 12:39-40

15. Covey SD, Wideman RD, McDonald C et al (2006) The pancreatic beta cell is a key site for mediating the effects of leptin on glucose homeostasis. Cell Metab 4:291-302

16. Wang MY, Chen L, Clark GO et al (2010) Leptin therapy in insulindeficient type I diabetes. Proc Natl Acad Sci USA 107:4813-4819

17. Yu X, Park BH, Wang MY, Wang ZV, Unger RH (2008) Making insulin-deficient type 1 diabetic rodents thrive without insulin. Proc Natl Acad Sci USA 105:14070-14075

18. Vieira E, Nilsson EC, Nerstedt A et al (2008) Relationship between AMPK and the transcriptional balance of clock-related genes in skeletal muscle. Am J Physiol Endocrinol Metab 295: E1032-E1037

19. Kubista M, Andrade JM, Bengtsson M et al (2006) The real-time polymerase chain reaction. Mol Aspects Med 27:95-125

20. Willey CD, Palanisamy AP, Johnston RK et al (2008) STAT3 activation in pressure-overloaded feline myocardium: role for integrins and the tyrosine kinase BMX. Int J Biol Sci 4:184-199

21. Moore F, Colli ML, Cnop M et al (2009) PTPN2, a candidate gene for type 1 diabetes, modulates interferon-gamma-induced pancreatic beta-cell apoptosis. Diabetes 58:1283-1291

22. McKinnon CM, Ravier MA, Rutter GA (2006) FoxO1 is required for the regulation of preproglucagon gene expression by insulin in pancreatic alphaTC1-9 cells. J Biol Chem 281:39358-39369

23. McGirr R, Ejbick CE, Carter DE et al (2005) Glucose dependence of the regulated secretory pathway in alphaTC1-6 cells. Endocrinology 146:4514-4523

24. Dumonteil E, Magnan C, Ritz-Laser B, Ktorza A, Meda P, Philippe J (2000) Glucose regulates proinsulin and prosomatostatin but not proglucagon messenger ribonucleic acid levels in rat pancreatic islets. Endocrinology 141:174-180

25. Fruhbeck $\mathrm{G}$ (2006) Intracellular signalling pathways activated by leptin. Biochem J 393:7-20

26. Saura M, Zaragoza C, Bao C, Herranz B, Rodriguez-Puyol M, Lowenstein CJ (2006) Stat3 mediates interleukin-6 [correction of interelukin-6] inhibition of human endothelial nitric-oxide synthase expression. J Biol Chem 281:30057-30062

27. Ramadoss P, Unger-Smith NE, Lam FS, Hollenberg AN (2009) STAT3 targets the regulatory regions of gluconeogenic genes in vivo. Mol Endocrinol 23:827-837

28. Guo Z, Jiang H, Xu X, Duan W, Mattson MP (2008) Leptinmediated cell survival signaling in hippocampal neurons mediated by JAK STAT3 and mitochondrial stabilization. J Biol Chem 283:1754-1763

29. Redmon JB, Towle HC, Robertson RP (1994) Regulation of human insulin gene transcription by glucose, epinephrine, and somatostatin. Diabetes 43:546-551

30. Zhao AZ, Shinohara MM, Huang D et al (2000) Leptin induces insulin-like signaling that antagonizes cAMP elevation by glucagon in hepatocytes. J Biol Chem 275:11348-11354

31. Gutiérrez-Juárez R, Obici S, Rossetti L (2004) Melanocortinindependent effects of leptin on hepatic glucose fluxes. J Biol Chem 279:49704-49715

32. Morrison CD, Morton GJ, Niswender KD, Gelling RW, Schwartz MW (2005) Leptin inhibits hypothalamic Npy and Agrp gene expression via a mechanism that requires phosphatidylinositol 3-OH-kinase signaling. Am J Physiol Endocrinol Metab 289:E1051-E1057

33. Kitamura T, Feng Y, Kitamura YI et al (2006) Forkhead protein FoxO1 mediates Agrp-dependent effects of leptin on food intake. Nat Med 12:534-540

34. Singh A, Wirtz M, Parker N et al (2009) Leptin-mediated changes in hepatic mitochondrial metabolism, structure, and protein levels. Proc Natl Acad Sci USA 106:13100-13105

35. Gonzalez M, Böer U, Dickel C et al (2008) Loss of insulininduced inhibition of glucagon gene transcription in hamster pancreatic islet alpha cells by long-term insulin exposure. Diabetologia 51:2012-2021

36. Goncz E, Strowski MZ, Grötzinger C et al (2008) Orexin-A inhibits glucagon secretion and gene expression through a Foxo1dependent pathway. Endocrinology 149:1618-1626

37. Niu G, Wright KL, Ma Y et al (2005) Role of Stat3 in regulating p53 expression and function. Mol Cell Biol 25:7432-7440

38. Inoue H, Ogawa W, Ozaki M et al (2004) Role of STAT-3 in regulation of hepatic gluconeogenic genes and carbohydrate metabolism in vivo. Nat Med 10:168-174

39. Kraus D, Herman MA, Kahn BB (2010) Leveraging leptin for type I diabetes? Proc Natl Acad Sci USA 107:4793-4794 